\title{
Effect of Foam and Liquid Bleomycin in the Management of Venous Malformations in Head and Neck Region. A Comparative Study
}

\author{
NADA A. MAHMOUD, M.D. \\ The Department of Plastic, Burn and Maxillofacial Surgery, Faculty of Medicine, Ain Shams University, Cairo, Egypt
}

\begin{abstract}
Background: Many treatment options for Venous Malformations (VM) has been documented in the literature but injection sclerotherapy has been considered a current mainstay for their treatment. We conducted this study to determine efficacy and durability of different injectable forms of bleomycin sclerotherapy in the treatment of VMs in cervico-facial region.
\end{abstract}

Patients and Methods: Thirty patients complaining of venous malformation in the head and neck region, diagnosed clinically and confirmed by magnetic resonance imaging, had been injected with bleomycin sclerosing material. They were divided into two equal groups according to the form of bleomycin injected; Group A: Foam form was injected and Group B: Liquid form was injected. Patient's data, anatomical sites, type and volume of the VM, number of injection sessions and the average dose of injected agents were documented and statistically compared between the 2 groups.

Results: MRI imaging showed a decline of more than $90 \%$ from the initial size of lesions in $66.7 \%$ cases and considerable decline $(60 \%-90 \%)$ in $33.3 \%$ of cases. In Group A the number of sessions were (1-4), while in Group B were (1-6). the amount of sclerosing material injected in Group A were (2-7.5mg), while in Group B were (3.5-13mg), which was statistically significant. The cumulative dose in the equal size lesions was lower in the foam form rather than the liquid one, and show statistically significant difference.

Conclusion: Foam form has greater promise compared with liquid form in the treatment of VMs and would encourage us to continue use the bleomycin in its foam form in the future on a bigger number of patients with larger size lesion and different location without reaching to the toxic cumulative life time dose.

Key Words: Venous malformations - Head and neck - Foam Liquid-Bleomycin.

\section{INTRODUCTION}

Venous Malformations (VMs) are the most common vascular malformations in the head and neck region. They usually affect multiple anatomical regions including; skin, mucosa, neuromuscular structure and bone [1,2].

These pathological conditions were commonly merged under the term hemangioma in the past. The work of Mulliken and Glowacki [3] has enabled better understanding of the distinction between different clinical entities, and they developed a classification based on histopathological findings divide these anomalies into vascular tumors and malformations. This classification was accepted by the International Society for the Study of Vascular Anomalies [4].

Hamburg Classification is a modified classification and it is a consensus of Congenital Vascular Malformation (CVM) experts who met at the $7^{\text {th }}$ International Workshop on Vascular Malformation [5]. This classification has shown its superiority in its clinical applicability and has been well accepted as the modern classification system." It shows minimum confusion because the terminology provides substantial information on the basis of embryologic development.

According to Hamburg classification, patients are divided into three categories: Those with localized or extensive subcutaneous lesions (limited $\mathrm{VMs}$ ), those with intramuscular infiltrations (infiltrating VMs) and those with complex-combined VMs which involve both extensive subcutaneous and intramuscular lesions [6,7].

Localized limited lesion, diffuse infiltrating lesion or even complex combined ones often cause symptoms due to compression of the surrounding structures as muscles and nerves [6]. If left untreated, they usually increase gradually in proportion to the normal growth of the body and may finally cause disfigurement and organs dysfunction in some cases.

Laser therapy, sclerotherapy, embolization, electrochemical therapy, copper needle treatment, surgical resection and a combination of these, have been used to treat VMs [8]. Injection sclerotherapy has been considered a current mainstay for treatment of VMs $[\mathbf{9 , 1 0 ]}$.

Variety of sclerosing agents had been used to treat these lesions but none of them was considered 
to be the best one [11-13]. Bleomycin in liquid form had emerged as a promising sclerosing agent for treatment of VMs [14]. Compared with sodium morrhuate and absolute ethanol; bleomycin does not result in ulceration and necrosis in skin and mucosa, no nerve injury with no reports of hematuria and neuropathy which makes it especially suitable for treating VMs in the cervico-facial region. Also bleomycin injection was associated with tolerable pain so, it can be used without general anesthesia [15-18].

Minimal side effects, fast recovery, good outcomes and low cost had led to increase the interest in bleomycin as a sclerosing agent although it can be absorbed systemically as reported by Siegel [19]. Dose-related pulmonary fibrosis was reported in some oncology patients receiving high cumulative doses of intravenous bleomycin [20]. The current recommended life time dose is less than $400 \mathrm{mg}$ or $5 \mathrm{mg} / \mathrm{kg}$ to reduce the risk of pulmonary fibrosis [16].

Few studies have reported the usage of sclerosing foam for the treatment of symptomatic VMs [21-25]. Yamaki et al., [26] proved the efficacy of polidaconal foam sclerotherapy in comparison with its liquid form. As the foam sclerosant includes the possibility of reducing the amount of necessary sclerosing solutions as well as the concentration with an acceptably low rate of adverse events. These findings suggested that foam form could have greater promise compared with liquid form in the treatment of VMs.

So, due to the dose limitation of bleomycin, we tried to use it in its foam form, as the foam form would allow extended sclerosation with a small amount of sclerosant.

Few studies had used bleomycin in its foam form, [27-30] however none of them compared its foamed form with the liquid one regarding the controlled limited total effective dose in both techniques and the total number of sessions required to treat it.

Therefore, we conducted this study to determine efficacy and durability of injection of foam bleomycin sclerotherapy compared with liquid bleomycin sclerotherapy in the treatment of VMs in cervico-facial region as regard the total number of session required and the amount of the bleomycin used in treatment for each form.

\section{PATIENTS AND METHODS}

This prospective, randomized, study was performed in the period from June 2015 to October
2017. Thirty patients with venous malformation in head and neck region diagnosed clinically and confirmed by magnetic resonance imaging to document the location and size of VMs through T1 and $\mathrm{T} 2$ intensity. In all cases of VMs the T1 was hypo intense and $\mathrm{T} 2$ was hyper intense were included. The volume of each lesion was also detected. Patients who underwent any previous treatment for the VMs were excluded from the study.

All patients suffered from swelling and cosmetic disfigurement, 13 of them complained of pain. They were divided equally into two groups using simple randomization. Group (A): Included 15 patients who were treated with foam sclerotherapy while Group (B): Included 15 patients who were treated with liquid sclerotherapy.

Bleomycin powder $(15 \mathrm{mg})$ was reconstituted into two dilutions for both forms (liquid and foam) to suit young and adult patients. For adult, Bleomycin powder $(15 \mathrm{mg})$ was reconstituted with $7.5 \mathrm{~mL}$ of normal saline (dilution $2 \mathrm{mg} / \mathrm{mL}$ ). For children Bleomycin powder $(15 \mathrm{mg})$ was reconstituted in $15 \mathrm{ml}$ saline (dilution $1 \mathrm{mg} / \mathrm{mL}$ ). We generated the bleomycin foam by re-suspending bleomycin solution in 25\% Human Serum Albumin (HSA) to reduce surface tension enough to create relatively stable foam [31]. Bleomycin foam was made by mixing this solution, 25\% HSA and room air in a 1:1:4 ratio (by volume), respectively, through a three-way stopcock.

Percutaneous injection sclerotherapy was done in both groups through a 24-gauge needle. The needle was inserted into the venous space followed by aspiration of blood to confirm its intraluminal position then the sclerosing solution (either foam or liquid) was infused slowly in horizontal direction from a healthy tissue.

The volume injected and the total number of sessions varied according to the size of VMs. During the injection in every session we stopped adding more sclerosant agent when the lesion gets engorged with blanching of covering mucosa or skin or reaching the maximum recommended dose of injected sclerosants; $7.5 \mathrm{mg}$ per session for children and $15 \mathrm{mg}$ per session for adult. After the treatment session completed, manual compression with a sterile gauze was done for 2-5 minutes to control oozing.

We continued injection until clinical involution of the lesion or when no more decrease in size two successive sessions and hence the number of sessions is determined and then a holdup period of six months was given to the patient to start postinjection evaluation. 


\section{Post-sclerotherapy follow-up:}

As T2 intensity was usually changed with treatment of the VMs, post-sclerotherapy surveillance using T2 signal intensity MRI was done for each $\mathrm{VM}$ at 6 months after last injection session and subjective analysis of before and after images to assess the degree of change.

The MRI findings were divided into four groups: (1) Complete decline: The venous space was reduced by more than $90 \%$, (2) Partial decline: The venous space show considerable reduction $(60 \%$ 90\%), (3) Minimal decline: The venous space show partial reduction (20\%-60\%), (4) Unchanged: The size of the lesion was the same.

Collection of patients' results from both groups and their evaluation was done at the end of the post-sclerotherapy follow-up period.

\section{Statistical analysis:}

Statistical analysis of data was performed with IBM computer using statistical program for social science (SPSS Inc., Chicago, USA). Quantitative variables were expressed as mean, $\mathrm{SD}$, ranges, median, and interquartile range. Qualitative variables were expressed as number and percentage. The Mann-Whitney test was used to compare two independent groups with quantitative data and nonparametric distribution and the Wilcoxon rank test was used to compare two paired groups with quantitative data and nonparametric distribution. Probability value was considered significant when $p$-value was less than 0.05 .

\section{RESULTS}

Follow-up period ranged from 6-10 months; mean 7.3 months. No major complications (as allergic reactions, deep vein thrombosis or pulmonary embolism) were recorded in both groups. Only one case in Group B had mucosal ulceration of the lower lip after injection which was managed conservatively. Patients' data from both groups are shown in (Tables 1,2).

Table (1): Patients' data in Group A.

\begin{tabular}{|c|c|c|c|c|c|c|c|}
\hline Case & Sex & Age & Site & Lesion type & Size of lesion & $\begin{array}{l}\text { Number of } \\
\text { Sessions }\end{array}$ & $\begin{array}{l}\text { Dosage per session/ } \\
\text { total amount injected }\end{array}$ \\
\hline 1 & Female & 2 & Tip of nose & Limited & $3 \times 2\left(6 \mathrm{Cm}^{2}\right)$ & 1 & $3 \mathrm{mg} / 3$ \\
\hline 2 & Male & 17 & Lower lip & Infiltrating & $7 \times 5\left(35 \mathrm{Cm}^{2}\right)$ & 3 & $7 \mathrm{mg} / 21$ \\
\hline 3 & Female & 14 & Right cheek & Infiltrating & $6 \times 8\left(48 \mathrm{Cm}^{2}\right)$ & 4 & $7.5 \mathrm{mg} / 30$ \\
\hline 4 & Male & 12 & Left cheek & Infiltrating & $5 \times 4\left(20 \mathrm{Cm}^{2}\right)$ & 2 & $5 \mathrm{mg} / 10$ \\
\hline 5 & Female & 3 & Lower lip & Infiltrating & $2 \times 2\left(4 \mathrm{Cm}^{2}\right)$ & 1 & $2 \mathrm{mg} / 2$ \\
\hline 6 & Female & 5 & Right cheek & Infiltrating & $2 \times 3\left(6 \mathrm{Cm}^{2}\right)$ & 1 & $3 \mathrm{mg} / 3$ \\
\hline 7 & Female & 6 & Chin & Infiltrating & $4 \times 4\left(16 \mathrm{Cm}^{2}\right)$ & 2 & $3.5 \mathrm{mg} / 7$ \\
\hline 8 & Male & 5 & Tip of nose & Limited & $2 \times 2\left(4 \mathrm{Cm}^{2}\right)$ & 1 & $2 \mathrm{mg} / 2$ \\
\hline 9 & Female & 7 & Left cheek & Infiltrating & $2 \times 3\left(6 \mathrm{Cm}^{2}\right)$ & 1 & $3 \mathrm{mg} / 3$ \\
\hline 10 & Male & 12 & Left temporal & Infiltrating & $4 \times 7\left(28 \mathrm{Cm}^{2}\right)$ & 2 & $6 \mathrm{mg} / 12$ \\
\hline 11 & Male & 11 & Lower lip & Infiltrating & $3 \times 4\left(12 \mathrm{Cm}^{2}\right)$ & 1 & $6 \mathrm{mg} / 6$ \\
\hline 12 & Male & 15 & Chin & Infiltrating & $4 \times 5\left(20 \mathrm{Cm}^{2}\right)$ & 2 & $5 \mathrm{mg} / 10$ \\
\hline 13 & Female & 22 & Right cheek & Infiltrating & $5 \times 6\left(30 \mathrm{Cm}^{2}\right)$ & 2 & $7.5 \mathrm{mg} / 15$ \\
\hline 14 & Male & 16 & Lower lip & Infiltrating & $2 \times 3\left(6 \mathrm{Cm}^{2}\right)$ & 1 & $3 \mathrm{mg} / 3$ \\
\hline 15 & Male & 8 & Right cheek & Infiltrating & $2 \times 2\left(4 \mathrm{Cm}^{2}\right)$ & 1 & $2 \mathrm{mg} / 2$ \\
\hline
\end{tabular}

Table (2): Patients' data in Group B.

\begin{tabular}{llllllcc}
\hline Case & Sex & Age & Site of lesion & Type & Size of lesion & $\begin{array}{c}\text { Number of } \\
\text { Sessions }\end{array}$ & $\begin{array}{c}\text { Dosage per session/ } \\
\text { total amount }\end{array}$ \\
\hline 1 & Male & 12 & Right cheek & Infiltrating & $5 \times 6\left(30 \mathrm{Cm}^{2}\right)$ & 3 & $10 \mathrm{mg} / 30$ \\
2 & Female & 17 & Right cheek & Infiltrating & $7 \times 6\left(42 \mathrm{Cm}^{2}\right)$ & 4 & $10 \mathrm{mg} / 40$ \\
3 & Female & 10 & Tongue & Infiltrating & $3 \times 4\left(12 \mathrm{Cm}^{2}\right)$ & 2 & $6 \mathrm{mg} / 12$ \\
4 & Female & 8 & Tongue & Limited & $3 \times 3\left(9 \mathrm{Cm}^{2}\right)$ & 2 & $4 \mathrm{mg} / 8$ \\
5 & Female & 12 & Right side of neck & Infiltrating & $7 \times 5\left(35 \mathrm{Cm}^{2}\right)$ & 4 & $11 \mathrm{mg} / 44$ \\
6 & Male & 7 & Chin & Limited & $2 \times 3\left(6 \mathrm{Cm}^{2}\right)$ & 1 & $7 \mathrm{mg} / 7$ \\
7 & Female & 2.5 & floor of mouth & Infiltrating & $3 \times 2\left(6 \mathrm{Cm}^{2}\right)$ & 2 & $3.5 \mathrm{mg} / 7$ \\
8 & Female & 5 & Lower lip & Limited & $2 \times 2\left(4 \mathrm{Cm}^{2}\right)$ & 1 & $4 \mathrm{mg} / 4$ \\
9 & Female & 12 & Right cheek & Infiltrating & $5 \times 4\left(20 \mathrm{Cm}^{2}\right)$ & 3 & $7 \mathrm{mg} / 21$ \\
10 & Male & 14 & Lower lip & Infiltrating & $8 \times 7\left(56 \mathrm{Cm}^{2}\right)$ & 6 & $13 \mathrm{mg} / 78$ \\
11 & Female & 16 & Left cheek & Infiltrating & $3 \times 5\left(15 \mathrm{Cm}^{2}\right)$ & 3 & $5 \mathrm{mg} / 15$ \\
12 & Female & 22 & Chin & Infiltrating & $5 \times 5\left(25 \mathrm{Cm}^{2}\right)$ & 3 & $9 \mathrm{mg} / 27$ \\
13 & Male & 14 & Lower lip & Infiltrating & $6 \times 4\left(24 \mathrm{Cm}^{2}\right)$ & 3 & $8 \mathrm{mg} / 24$ \\
14 & Male & 18 & Left temporal & Infiltrating & $5 \times 9\left(45 \mathrm{Cm}^{2}\right)$ & 6 & $9 \mathrm{mg} / 54$ \\
15 & Male & 24 & floor of mouth & Infiltrating & $6 \times 8\left(48 \mathrm{Cm}^{2}\right)$ & 6 & $11 \mathrm{mg} / 66$ \\
\hline
\end{tabular}


Fourteen patients were males $(46.6 \%)$ and sixteen were females (53.3\%). The mean age of the patients was $12.7 \pm 17.4$ years (ranged from 2 to 24 years). There were no significant differences in age and sex ratio in both groups as shown in (Table 3).

The anatomical sites of the VM were as follows; the cheek in 10 patients $(33.3 \%)$, lower lip in 7 patients (23.3\%), tip of nose in 2 patients $(6.7 \%)$, tongue in 2 patient $(6.7 \%)$, chin in 4 patients $(13.3 \%)$, temporal region in 2 patients $(6.7 \%)$, neck region in 1 patient $(3.3 \%)$ and the floor of mouth in 2 patients $(6.7 \%)$. The two-dimensional pre injection size of the lesion ranged between 2 $X 2 \mathrm{~cm}$ and $8 \times 7 \mathrm{~cm}$, there were no significant differences in size of lesion in both groups as shown in (Table 3 ).

The most common type in the study was infiltrating type $(83.3 \%)$; in Group (A) it formed $86.7 \%$ of patients compared to $80 \%$ of patients of Group B, There were no significant differences concerning type of lesion in both groups as shown in (Table 3).

Number of injection sessions in Group A ranged from 1-4 sessions; mean 1.7 session, while in Group B it ranged from 1-6 sessions; mean 3.3 sessions. Patients who had only one session were eight in Group A (53.3\%) and two in Group B $(13.3 \%)$. Five patients in Group A $(33.3 \%)$ and three in Group B (20\%) had two sessions. One patient in Group A (6.6\%) and four in Group B (26.6\%) had three sessions. However, the patients that had more than three session were one in Group A $(6.6 \%)$ and six in Group B (40\%). These data were statistically significant as shown in (Table $3)$.

In Group A the average dose was 2-7mg per session according to the size of the lesion, however, it was 4-13mg per session in Group B. These data were statistically significant as shown in (Table $3)$.

Follow-up MRI imaging was done 6 months after the last session, subjective analysis of T2 signal intensity showed that VMs became hypo tense in all treated patient in both groups.

MRI demonstrated reduction of the venous space by more than $90 \%$ of the initial size in 13 patients of Group A and 10 patients of Group B (86.7\%-66.7\% respectively), indicating a significant difference between both groups (0.001). Venous space showed considerable reduction in 2 patients of Group A and 5 patients of Group B (13.3\%$33.3 \%$ respectively) and this also indicating a significant difference between both groups ( $p$ value 0.002). None of the patients treated in both groups showed minimal or no reduction of the lesion compared to the initial size Figs. $(1,2)$.

To validate efficacy of the injectable material, we tried to correlate the results obtained for patients $(n=20)$ with similar type and equal sized lesions that had the same degree of reduction of venous space from both groups regarding the number of sessions, amount of material injected per session and total amount of material used (Table 4).

In patients with limited type lesions and small in size (less than $6 \mathrm{~cm}^{2}$ ) showed no significance difference concerning the total amount of injection between both groups. However, in patients with infiltrating type and large sized lesions, Group A gave same result as in Group B but with less number of sessions, less amount of sclerosant injection per session and also with less total amount of sclerosing material than Group B. This difference between similar type lesions with equal size showed to be of statistically significant difference concerning the total amount of injecting material used between the 2 groups as shown in (Table 4).

Table (3): Differences between both groups as regards the age, sex, type of lesion, size, total number of sessions, the amount of sclerosant injected per session and the total amount of sclerosant used.

\begin{tabular}{|c|c|c|c|}
\hline & $\begin{array}{l}\text { Group A } \\
\text { (Foam) }\end{array}$ & $\begin{array}{l}\text { Group B } \\
\text { (Liquid) }\end{array}$ & $\begin{array}{c}p- \\
\text { value }\end{array}$ \\
\hline \multicolumn{4}{|l|}{ Age: } \\
\hline Average & $2-22$ & $2-24$ & \\
\hline Mean & 10.3 & 12.7 & 0.324 \\
\hline \multicolumn{4}{|l|}{ Sex: } \\
\hline Male & 8 & 6 & 0.761 \\
\hline Female & 7 & 9 & 0.787 \\
\hline \multicolumn{4}{|l|}{ Type: } \\
\hline Infiltrating & 13 & 12 & 0.923 \\
\hline Localized & 2 & 3 & 0.671 \\
\hline \multicolumn{4}{|c|}{ Two dimensional size of lesion: } \\
\hline Average $\left(\mathrm{cm}^{2}\right)$ & $4-48$ & $4-56$ & \\
\hline Mean $\left(\mathrm{cm}^{2}\right)$ & 16.3 & 25.1 & \\
\hline \multicolumn{4}{|c|}{ Number of sessions: } \\
\hline Average & $1-4$ & $1-6$ & \\
\hline Mean & 1.7 & 3.3 & $0.023 *$ \\
\hline \multicolumn{4}{|c|}{ Amount of injection per session: } \\
\hline Average (mg) & $2-7.5$ & $3.5-13$ & \\
\hline Mean (mg) & 4.4 & 7.8 & $0.014 *$ \\
\hline \multicolumn{4}{|c|}{ Total amount of injection: } \\
\hline Average (mg) & $2-30$ & $4-78$ & \\
\hline Mean (mg) & 8.6 & 29 & $0.012 *$ \\
\hline
\end{tabular}

*: Indicate significance difference. 
Table (4): Differences in the same sized lesion with the same degree of improvement in both groups as regards the total number of sessions, the amount of sclerosant injected per session and the total amount of sclerosant used.

\begin{tabular}{|c|c|c|c|c|c|c|c|c|}
\hline & $\begin{array}{l}\text { Size of } \\
\text { the lesion }\end{array}$ & Type & Location & $\begin{array}{l}\text { No. of patients/ } \\
\text { Age of each one }\end{array}$ & $\begin{array}{l}\text { No. of } \\
\text { sessions }\end{array}$ & $\begin{array}{c}\text { Amount of } \\
\text { sclerosant injected } \\
\text { per session }\end{array}$ & $\begin{array}{c}\text { Total } \\
\text { amount of } \\
\text { sclerosant used }\end{array}$ & $\begin{array}{c}p- \\
\text { value }\end{array}$ \\
\hline Group A & $4 \mathrm{Cm}^{2}$ & Limited & Nose & $1 / 3$ years & 1 & $2 \mathrm{mg}$ & $2 \mathrm{mg}$ & 0.921 \\
\hline Group B & $4 \mathrm{Cm}^{2}$ & Limited & Lip & $1 / 2$ years & 1 & $4 \mathrm{mg}$ & $4 \mathrm{mg}$ & \\
\hline \multirow[t]{2}{*}{ Group A } & \multirow[t]{2}{*}{$6 \mathrm{Cm}^{2}$} & Infiltrating & \multirow[t]{2}{*}{ Cheek nose } & $1 / 5$ years & \multirow[t]{2}{*}{1} & $3 \mathrm{mg}$ & $3 \mathrm{mg}$ & \multirow[t]{2}{*}{$0.039 *$} \\
\hline & & limited & & $1 / 2$ years & & $3 \mathrm{mg}$ & $3 \mathrm{mg}$ & \\
\hline \multirow[t]{2}{*}{ Group B } & \multirow[t]{2}{*}{$6 \mathrm{Cm}^{2}$} & Infiltrating & \multirow[t]{2}{*}{ Mouth chin } & $1, / 2.5$ years & \multirow[t]{2}{*}{1} & $3.5 \mathrm{mg}$ & \multirow{2}{*}{$\begin{array}{l}7 \mathrm{mg} \\
7 \mathrm{mg}\end{array}$} & \\
\hline & & limited & & $1 / 7$ years & & $7 \mathrm{mg}$ & & \\
\hline Group A & $12 \mathrm{Cm}^{2}$ & Infiltrating & Lip & $1 / 11$ years & 1 & $6 \mathrm{mg}$ & $6 \mathrm{mg}$ & \multirow[t]{2}{*}{$0.031 *$} \\
\hline Group B & $12 \mathrm{Cm}^{2}$ & Infiltrating & Tongue & $1 / 10$ years & 2 & $6 \mathrm{mg}$ & $12 \mathrm{mg}$ & \\
\hline Group A & $20 \mathrm{Cm}^{2}$ & Infiltrating & Cheek & $1 / 12$ years & 2 & $5 \mathrm{mg}$ & $10 \mathrm{mg}$ & \multirow[t]{2}{*}{$0.023^{*}$} \\
\hline Group B & $20 \mathrm{Cm}^{2}$ & Infiltrating & Cheek & $1 / 12$ years & 3 & $7 \mathrm{mg}$ & $21 \mathrm{mg}$ & \\
\hline Group A & $30 \mathrm{Cm}^{2}$ & Infiltrating & Cheek & $1 / 22$ years & 2 & $7.5 \mathrm{mg}$ & $15 \mathrm{mg}$ & \multirow[t]{2}{*}{$0.021 *$} \\
\hline Group B & $30 \mathrm{Cm}^{2}$ & Infiltrating & Cheek & $1 / 12$ years & 3 & $10 \mathrm{mg}$ & $30 \mathrm{mg}$ & \\
\hline Group A & $35 \mathrm{Cm}^{2}$ & Infiltrating & Lip & $1 / 17$ years & 3 & $7 \mathrm{mg}$ & $21 \mathrm{mg}$ & \multirow[t]{2}{*}{$0.019 *$} \\
\hline Group B & $35 \mathrm{Cm}^{2}$ & Infiltrating & Neck & $1 / 12$ years & 4 & $11 \mathrm{mg}$ & $44 \mathrm{~m}$ & \\
\hline Group A & $48 \mathrm{Cm}^{2}$ & Infiltrating & Cheek & $1 / 14$ years & 4 & $7.5 \mathrm{mg}$ & $30 \mathrm{mg}$ & \multirow[t]{2}{*}{$0.012 *$} \\
\hline Group B & $48 \mathrm{Cm}^{2}$ & Infiltrating & Mouth & $1 / 24$ years & 6 & $11 \mathrm{mg}$ & $66 \mathrm{mg}$ & \\
\hline
\end{tabular}
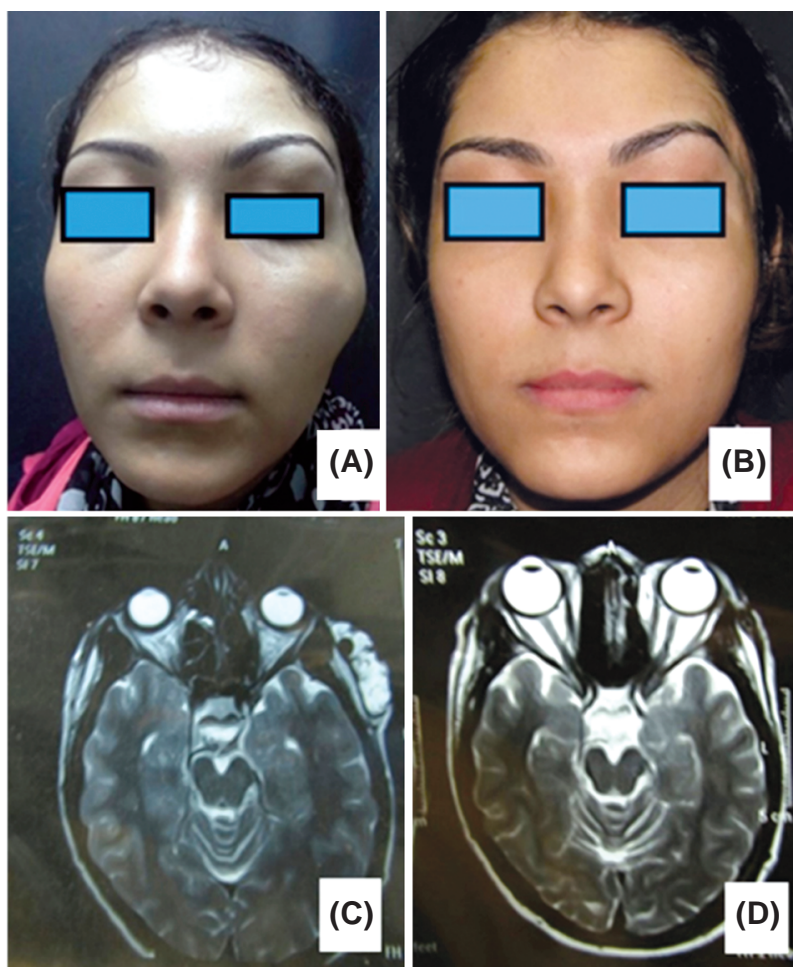

Fig. (1): (A) Female patient 22 years old with infiltrated type VM of the left cheek (5 X 6). (B) After two session of iniection of $7.5 \mathrm{mg} / \mathrm{ml}$ of foamed bleomycin. (C) The lesion before injection showed a hypertense T2 in the left cheek. (D) Follow-up MRI after 6 months of the injection showing disaperance of the lesion.

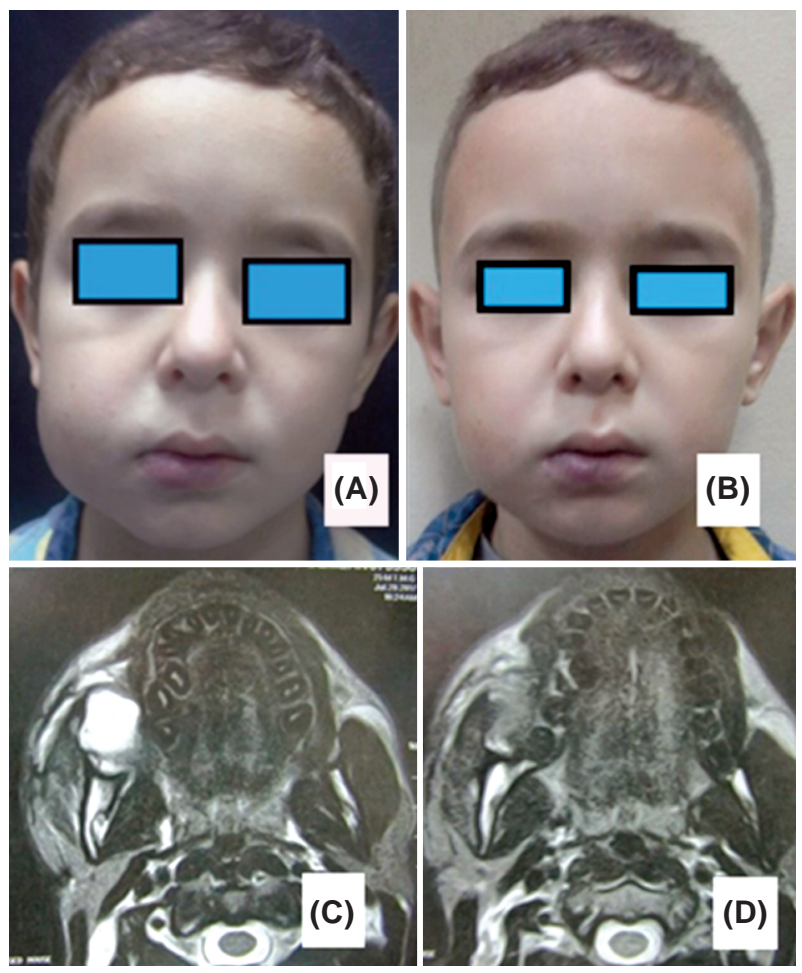

Fig. (2): (A) Male patient 12 years old had infiltrated type VM of the right cheek $(5 \times 6)$ in addition to small extension of the lower lip (1 X 2). (B) After three session of iniection of $10 \mathrm{mg} / \mathrm{ml}$ of liquid bleomycin (C) The lesion before injection showed a hypertense T2 in the right cheek and lower lip. (D) Follow-up MRI after 6 months of the injection showing disaperance of the lesion. 


\section{DISCUSSION}

Bleomycin is cytotoxic antitumor agent that proved to be effective in treatment of VMs [32]. It inhibits DNA synthesis leading to cell death with minimal inflammation and swelling. This may be attributed to endothelial cell death via apoptosis rather than necrosis [33-36].

In 1977, Yura et al., [37] first used it as a sclerosing agent in lymphangiomas. In 1987 Tanigawa [38] injected it into aspirated cyst cavities in cystic hygroma. Since then, there were several reports using bleomycin as a sclerosing agent for vascular malformations in radiologic and surgical literatures [39-42].

One of the main concerns with bleomycin is the reported risk of pulmonary fibrosis associated with a cumulative life time dose of $400 \mathrm{mg}$, therefore, the concentration and dosage of drug are very important [43]. Toxicity risk with bleomycin is considered to be minimal if the dose is kept at or lower than $1 \mathrm{mg} / \mathrm{kg}$ per session, and used no more frequently than an interval of 3 weeks with total dose limited to $5 \mathrm{mg} / \mathrm{kg}$ [18]. The doses were always far below those used for anti-neoplastic indications [44].

In the present study, we aimed to determine efficacy and durability of injection of different forms of bleomycin sclerotherapy in the treatment of 30 patients with VMs in the cervico-facial region. We determined the 2D size of the lesion both clinically and radiologically using MRI images. In our study, we used two dilutions to prepare both forms in order to suit young and adult patients with no fear of dose-related complications, moreover, the dose using bleomycin liquid did not exceed the standard dose; also we kept an interval of 4 weeks between injections. Our study recorded decline more than $90 \%$ in MRI imaging in $66.7 \%$ cases, and considerable decline (60\%-90\%) in $33.3 \%$ of cases which were not required surgery later on, with accepted aesthetic appearance.

Minimal decline or unchanged size were not recorded in our cases using bleomycin liquid sclerotherapy. So, this simple non-invasive technique is quite an effective tool in the management of venous malformations. However, decreasing dose should be targeted with the use of bleomycin sclerotherapy to help in the management of lager lesions without dose related complication. This can be accomplished by combining it with other agents such as STS foam [45], or using it in its foam form.
Foaming may slow the rate of bleomycin washout from VMs, thereby reducing systemic concentration and the risk of toxicity [27].

In this study we used bleomycin vial (15mg) for treatment of VMS in its liquid and foam forms with a great caution to the administrated dose and that's why we used two dilutions to avoid any doserelated complications in both age groups (young and adults). All patients were injected in the outpatient clinic requiring only topical anesthetic cream, precluding the risk of anesthesia and also saving the cost of a long hospital staying.

In our study we did use the traditional method of injection as described in previous studies; $[27,46]$ this is a relatively easy and cost effective methods but needs a good level of experience and so ultrasound-guided injection would be more helpful to know that the correct space at which the sclerosing agent was injected [47], and we could consider this as a possible limitation of the study.

For evaluation of the final MRI findings of injection on the MRI, previous studies had used the term "cured" to describe lesions reduced by $90 \%$ with a follow-up period of nearly 6 months [47]. In the present study we used the term "decline" as it is untrue to give a patient a "cured" stamp after 6 months of treatment as small VM can increase in size again. For a diagnosis of a "cured VM" nothing should be visible on MRI at least one year of follow-up is necessary.

In Group A the total number of sessions, the average dose per session and the total amount of sclerosant material injected were less than Group $B$. This could be attributed to the higher average lesions size in Group B $\left(25.1 \mathrm{~cm}^{2}\right)$ were than in Group A $\left(16.3 \mathrm{~cm}^{2}\right)$. Although it is a blind randomized study we decided to validate the results by correlating same sized lesions with same type in (Table 4) which revealed that the cumulative dose in the equal size lesion was statistically lower in the foam form rather than the liquid one. This correlation proved that the foam form is of higher efficacy than liquid apart from the size of the lesion.

Although similar size VM of the same type in the same range of age were compared between the two groups in Table (4), not all locations were the same (except for 2 sizes) and so we consider this issue one of the limitations of the study. We recommend that in future studies comparison between foam and liquid forms should be done to lesions of same size, type, location and age group as location difference may also have an influence on outcomes. 
Although all of the lesions that required multiple session in Group B, the total cumulative dose after 6 session were still lower than the risked dose for pulmonary fibrosis. The smaller number of session in Group A rather than Group B may be due to the air containing bubbles in the foam form, so it had more time contact with endothelial lining than the liquid form.

Foamed bleomycin provides more volume per unit of drug, less cumulative dose and less cost as well. These differences encourage us to use the bleomycin in its foam form.

Few studies used bleomycin foam in treatment of venous malformations. Ul Haq et al., [27] showed positive clinical outcomes in twenty patients treated with bleomycin foam. However, they didn't clarified the size of the lesion in those patients to easily correlate the number of session with the different size of the lesion. They used another sclerosant material in one case and the post-treatment MRI findings weren't present in all cases.

Azene et al., [28] also used the bleomycin in its foam form on five patients, in three cases of them they combined the therapy with ethanol and their assessment occurred per session. They proved that the use of foamed bleomycin is effective for the percutaneous treatment of VMs, but their study has limited number of patients.

In the present study we concluded that foamed bleomycin may help to solve the problem of bleomycin dose limitation, as it provides more volume per unit of drug and less cumulative dose which is helpful to cover large vascular malformations with less number of sessions, minimal amount of solution with an acceptably lower rate of adverse events and less cost as well.

These findings suggest that foam form could have greater promise compared with liquid form in the treatment of VMs and would encourage us to continue use the bleomycin in its foam form in the future on a bigger number of patients with larger sizes and different locations.

\section{REFERENCES}

1- Derby L.D. AND Low D.W.: Laser treatment of facial venous vascular malformations. Ann. Plast. Surg., 38: 371-8, 1997.

2- Mahady K., Thust S., Berkeley R., Stuart S., Barnacle A., Robertson F. and Mankad K.: Vascular anomalies of the head and neck in children. Quant. Imaging Med. Surg., Dec., 5 (6): 886-97, 2015.

3- Mulliken J.B. and Glowacki J.: Hemangiomas and vascular malformations in infants and children: A classification based on endothelial characteristics. Plast. Reconstr. Surg., 69: 412Y420, 1982.

4- ISSVA classification for vascular anomalies@ (approved at the International Society for the Study of Vascular Anomalies workshop, Melbourne, April 2014). Available from URL: issva.org/classification (accessed October 2016).

5- Lee B.B.: Critical issues on the management of congenital vascular malformation. Ann. Vasc. Surg., 18: 380-92, 2004.

6- Belov S.: Anatomopathological classification of congenital vascular defects. Semin. Vasc. Surg., 6 (4): 219-24, 1993.

7- Belov S.T.: Classification of congenital vascular defects. Int. Angiol., 9: 141-6, 1990.

8- Deveikis J.P.: Percutaneous ethanol sclerotherapy for vascular malformations in the head and neck. Arch. Facial Plast. Surg., 7: 322-5, 2005.

9- Greene A.K. and Alomari A.I.: Management of venous malformations. Clin. Plast. Surg., 38: 83-93, 2011.

10- Sachin K., Rashmi S., Manish S., et al.: Haemangiomas and venous malformations of the head and neck: A retrospective analysis of endovascular management in 358 patients. Indian J. Plast. Surg., 109-16, 2013.

11- Legiehn G.M. and Heran M.K.: Classification, diagnosis, and interventional radiologic management of vascular malformations. Orthop. Clin. North Am., 37: 435-74, 2006.

12- Legiehn G.M. and Heran M.K.: Venous malformations: Classification, development, diagnosis, and interventional radiologic management. Radiol. Clin. North Am., 46: 545-97, 2008

13- Zheng J.W., Yang X.J., Wang Y.A., et al.: Intralesional injection of Pingyangmycin for vascular malformations in oral and maxillofacial regions: An evaluation of 297 consecutive patients. Oral Oncol., 45: 872-6, 2009.

14- Yang Y., Sun M., Ma Q., et al.: Bleomycin A5 sclerotherapy for cervico-facial lymphatic malformations. J. Vasc. Surgery, 53: 150-5, 2011.

15- Yang Y., Sun M., Cheng X., et al.: Bleomycin A5 plus dexamethasone for control of growth in infantile parotid hemangiomas. Oral Surg. Oral Med. Oral Pathol. Oral Radiol Endod., 108: 62-9, 2009.

16- Muir T., Kirsten M., Fourie P., et al.: Intralesional Bleomycin Injection (IBI) treatment for haemangiomas and congenital vascularmal formations. Pediatr. Surg. Int., 19: 766-73, 2004.

17- Zhao J.H., Zhang W.F. and Zhao Y.F.: Sclerotherapy of oral and facial venous Malformations with use of pingyangmycin and/or sodium morrhuate. Int. J. Oral Maxillo. Fac. Surg., 33: 463-6, 2004.

18- Zhi K., Wen Y., Li L., et al.: The role of intralesional Pingyangmycinin the treatment of venous malformation official and maxillary region. Int. J. Pediatr. Otorhinolaryngol., 72: 593-7, 2008.

19- Seigel R.D. and Schiffman F.J.: Systemic toxicity following intracavitatory administration of bleomycin, Chest, 98 (2): 507, 1990. 
20- Luce J.K.: Clinical trial of bleomycin in solid tumours and lymphomas. Proc. Am. Assoc. Cancer Res., 10: 38, 1969.

21- Tessari L., Cavezzi A. and Frullini A.: Preliminary experience with a new sclerosing foam in the treatment of varicose veins. Dermatol. Surg., 27: 58-60, 2001.

22- Yamaki T., Nozaki M., Fujiwara O., et al.: Duplex-guided foam sclerotherapy for the treatment of the symptomatic venous malformations of the face. Dermatol. Surg., 28: 619-22, 2002

23- Cabrera J., Cabrera J. Jr., Garcia-Olmedo A. and Redondo P.: Treatment of venous malformations with sclerosant in microform foam. Arch. Dermatol., 139: 1409-16, 2003.

24- Pascarella L., Bergan J.J., Yamada C. and Mekenas L.: Venous angiomata: Treatment with sclerosant foam. Ann. Vasc. Surg., 19: 457-64, 2005.

25- Bergan J., Pascarella L. and Mekenas L.: Venous disorders: Treatment with sclerosant foam. J. Cardiovasc. Surg., 47: 115-24, 2005

26- Yamaki T., Nozaki M., Sakurai H., et al.: Prospective randomized efficacy of ultrasoundguided foam sclerotherapy compared with ultrasound-guided liquid sclerotherapy in the treatment of symptomatic venous malformations, Journal of Vascular Surgery, March, 578-84, 2008.

27- Ul Haq F., Mitchell S.E., Tekes A. and Weiss C.R.: Bleomycin foam treatment of venous malformations: A promising agent for effective treatment with minimal swelling. J. Vasc. Interv. Radiol., 26: 1484-93, 2015.

28- Azene E., Mitchell S., Radvany M., et al.: Foamed Bleomycin Sclerosis of Airway Venous Malformations: The Role of Interspecialty Collaboration Laryngoscope, 126: 2726-32, 2016

29- Berenstein A.: E-059 Bleomycin Sclerotherapy for Eyelid Venous Malformations as an Alternative to Surgery or Laser Therapy Journal of Neuro Interventional Surgery, 8: A74, 2016

30- Xiaofan Pan and Dylan Wolman: Percutaneous bleomycin foam effectively treats venous malformations. July 13, 2015.

31- Cooper A. and Kennedy M.W.: Biofoams and natural protein surfactants. Biophys. Chem., 151: 96-104, 2010.

32- Zhang W., Chen G., Ren J.G., et al.: Bleomycin induces endothelial mesenchymal transition through activation of mTOR pathway: A possible mechanism contributing to the sclerotherapy of venous malformations. Br. J. Pharmacol., 170: 1210-20, 2013.

33- Huang Y., Li P., Xia S., et al.: Proapoptotic effect and the mechanism of action of pingyangmycin on cavernous hemangiomas. Exp. Ther. Med., 7: 473-7, 2014.

34- Mabeta P. and Davis P.F.: The mechanism of bleomycin in inducing haemangioma regression. S Afr. Med. J., 98: 538-9, 2008.
35- Li P., Li D., Guo Z., et al.: Therapeutic mechanism of bleomycin A5 on infancy hemangioma: an experimental study. Zhonghua Kou Qiang Yi Xue Za Zhi, 48: 18-22, 2003.

36- Li P., Xiao X. and Guo Z.: Effect of bleomycin A5 on the hemangioma-derived endothelial cell line XTPS-1. Zhonghua Kou Qiang Yi Xue Za Zhi, 47: 324-8, 2012.

37- Yura J., Hashimoto T., Tsuruga N., et al.: Bleomycin treatment for cystic hygroma in children. Nihon Geka Hokan, 46: 607-14, 1977.

38- Tanigawa N., Shimomatsuya T., Takahashi L., et al.: Treatment of cystic hygroma and lymphangioma with the use of bleomycin fat emulsion. Cancer, 60: 741-9, 1987.

39- Muir T., Kirsten M., Fourie P., et al.: Intralesional Bleomycin Injection (IBI) treatment for haemangiomas and congenital vascular malformations. Pediatr. Surg. Int., 19: 766-73, 2004.

40- Mathur N.N., Rana I., Bothra R., et al.: Bleomycin sclerotherapy in congenital lymphatic and vascular malformations of head and neck. Int. J. Pediatr. Otorhinolaryngol., 69: 75-80, 2005.

41- Sainsbury D.C., Kessell G., Fall A.J., et al.: Intralesional bleomycin injection treatment for vascular birthmarks: A 5-year experience at a single United Kingdom Unit. Plast. Reconstr. Surg., 127: 2031-44, 2011.

42- Baskin D., Tander B. and Bankaoglu M.: Local bleomycin injection in the treatment of lymphangioma. European Journal of Pediatric Surgery: Official journal of Austrian Association of Pediatric Surgery. [et al.]=Zeitschrift fur Kinderchirurgie, 15: 383-6, 2005.

43- Mowad C.M., Nguyen T.V., Elenitsas R., et al.: Bleomycininduced flagellate dermatitis: A clinical and histopathological review. Br. J. Dermatol., 131: 700-02, 1994.

44- Sung M.W., Chang S.O., Choi J.H., et al.: Bleomycin sclerotherapy in patients with congenital and lymphatic malformation in the head and neck. Am. J. Otolaryngol., 16: 236-41, 1995.

45- Gregorya S., Burrows P.E., Ellinas H., et al.: Combined Nd: YAG laser and bleomycin sclerotherapy under the same anesthesia for cervicofacial venous malformations: A safe and effective treatment option. International Journal of Pediatric Otorhinolaryngology, 108: 30-4, 2018.

46- Lee H.J., Kim T.W., Kim J.M., et al.: Percutaneous sclerotherapy using bleomycin for the treatment of vascular malformations. International Journal of Dermatology, 56: 1186-91, 2017.

47- Hou R., Guo J., Hu K., Yang Y., et al.: A clinical study of ultrasound-guided intralesional injection of bleomycin A5 on venous malformation in cervical-facial region in China. J. Vasc. Surg., Vol. 51, 940-5, 2010. 